\title{
PREVALENCE OF KINESIOPHOBIA IN YOUNG ADULTS POST ACL RECONSTRUCTION
}

\section{Rahul Chaitanya Shah ${ }^{1}$, James Ghagare *2, Ashok Shyam ${ }^{3}$, Parag Sancheti ${ }^{4}$.}

${ }^{1}$ BPTh, Sancheti Institute College of Physiotherapy, Pune, Maharashtra, India.

*2 M PTh, Assistant Professor, Sancheti Institute College of Physiotherapy, Pune, M aharashtra,India.

${ }^{3}$ MS (Ortho) Research Officer, Sancheti Institute for Orthopaedics and Rehabilitation, Pune, Maharashtra, India.

${ }^{4}$ MS (Ortho) and Chairman, Sancheti Institute for Orthopaedics and Rehabilitation, Pune, Maharashtra, India.

\section{ABSTRACT}

Background and Purpose: Anterior cruciate ligament injuries are the most commonly affecting ligamentous injury in the lower limb which leads to reduced dynamic knee stability, functions and its associated factors result in reduced ability of returning to preinjuy level. Kinesiophobia (fear of reinjury) is the most cited reason for disappointing results post $A C L$ reconstruction. Hence, this study was performed to find the if there is a Prevalence of Kinesiophobia in young adults post Anterior cruciate ligament reconstruction.

Materials and Methods: A cross-sectional study with 201 subjects of young adult age group (18-35years) was chosen by convenient sampling method was performed. The participants were 4 to 8 weeks post Anterior cruciate ligament reconstruction (even mensical injuries were included) and were self ambulatory with $100 \%$ weight bearing. They were made to fill the Tampa Scale of Kinesiophobia in which scores above 37 were categorized as Kinesiophobic.

Results and Discussion: The mean age was $25.72 \pm 4.47$ and the prevalence of Kinesiophobia was positive in 124 out of 201 subjects, which is $61.69 \%$ prevalence. Also results proved that, women (67.44\%) are a higher risk of kinesiophobia than males (60.12\%). This study shows that there is Kinesiophobia in majority of patients after Anterior cruciate ligament reconstruction surgery.

Conclusion: This study concludes that there is high prevalence (61.69\%) of kinesiophobia in Young adults post ACL reconstruction at 4 to 8 weeks.

KEY WORDS: Ligamentous Injury, Tampa Scale Of Kinesiophobia ( TSK ), Fear Of Reinjury , Preinjury Level .

Address for correspondence: Dr. James Ghagare, Associate Professor, Sancheti Institute College of Physiotherapy, Sancheti Healthcare Academy, 11/12 Thube Park, Shivajinagar, Pune - 411005, Maharashtra, India. E-Mail: doc.ashokshyam@gmail.com

\begin{tabular}{|c|c|c|}
\hline \multicolumn{3}{|c|}{ Access this Article online } \\
\hline \multirow{2}{*}{$\begin{array}{c}\text { Quick Response code } \\
\text { Dol: 10.16965/ijpr.2016.172 }\end{array}$} & \multicolumn{2}{|c|}{$\begin{array}{l}\text { International Journal of Physiotherapy and Research } \\
\text { ISSN } 2321-1822 \\
\text { www.ijmhr.org/ ijpr.html }\end{array}$} \\
\hline & $\begin{array}{l}\text { Received: 25-08-2016 } \\
\text { Peer Review: 25-08-2016 } \\
\text { Revised: None }\end{array}$ & $\begin{array}{l}\text { Accepted: } 29-09-2016 \\
\text { Published (O): 11-02-2017 } \\
\text { Published (P): 11-02-2017 }\end{array}$ \\
\hline
\end{tabular}

\section{INTRODUCTION}

The Knee joint is the one of the most important joint in the pertaining to its functions of providing great stability, movement and weight bearing function. Dynamic knee stability is af- fected by both passive (ligamentous) and active (neuromuscular) joint restraints. Among the contributors to knee joint stability, the anterior cruciate ligament $(A C L)$ has long been considered the primary passive restraint to 
anterior translation of the tibia with respect to the femur [1,2]. ACL also contributes to the rotational stability in frontal and transverse planes due to its orientation $[3,4]$. Surgical reconstruction is commonly used to manage $\mathrm{ACL}$ injuries, presumably because surgery restores mechanical knee stability, which, in turn, is thought to promote optimal knee function. Functional outcome after ACL reconstruction is not uniform though, and up to $60 \%$ of the population does not return to preinjury, high-demand activities. Reduced knee function postsurgery has been attributed to a variety of residual impairments, including knee symptoms (eg, swelling, pain or instability), loss of knee motion, and thigh muscle weakness. Although some authors have speculated that altered psychosocial factors, such as elevated fear of reinjury, can reduce functional level, this area has not been extensively explored [5].

Kinesiophobia is said to be the fear of movement or the fear of reinjury. Kinesiophobia is the most extreme form of fear of movement, and is defined as an excessive, irrational and debilitating fear of physical movement and activity resulting from a feeling of vulnerability to painful injury or reinjury [6]. This way kinesiophobia has affected effective rehabilitation, reducing the productivity. The most commonly used method to assess kinesiophobia is Tampa Scale of Kinesiophobia ( TSK ). Kinesiophobia is basically a psychometric factor which affects the functions cause the individual would have a fear of reinjury. Despite reports demonstrating goodto-excellent results, only $65 \%$ to $70 \%$ of patients return to their preinjury level of sports activity following anterior cruciate ligament reconstruction. Psychological factors may contribute to this performance disparity $[7,8]$.

Tampa scale of Kinesiophobia (TSK) was developed by R. M iller, S. Kopri, and D. Todd, in 1991. The TSK is a 17-item self report checklist using a 4-point Likert scale that was developed as a measure of fear of movement or (re)injury. Kinesiophobia is defined by the developers as "an irrational, and debilitating fear of physical movement and activity resulting from a feeling of vulnerability to painful injury or re-injury [9] The scale is based on the model of fear avoidance, fear of work related activities, fear of movement and fear of re-injury [10]. Each question is rated between 1 to 4 as per 'strongly disagree' to 'strongly agree' . Questions 4,8,12 and 16 are inversely scored. The total score ranges between 17 and 68. A high value on the TSK indicates a high degree of kinesiophobia, and a cutoff score was developed by Vlaeyen (1995), where a score of 37or over is considered as a high score, while scores below that are considered as low scores.

Aim: To study the prevalence of Kinesiophobia in young adults post ACL reconstruction surgery.

\section{MATERIALS AND METHODS}

Procedure: This study was performed on 201 subjects in between the age group 18 to 35 years who had undergone an $\mathrm{ACL}$ reconstruction surgery 4 to 8 weeks ago, of which full weight bearing and ambulatory patients were included while those with PCL involvement, LM T and M M T repair surgery and any lower limb fractures were excluded from the study.

This was a cross-sectional study performed with a convenient sampling method. The participants were explained about the study and their role in it. A written consent for participation was taken. Tampa Scale of Kinesiophobia was used and its score was the outcome meaure to analyze the study. They were explained about the Tampa Scale of Kinesiophobia (TSK) and were then asked to fill it. Their scores were then calculated and analysis was done.

\section{RESULTS AND DISCUSSION}

The study revealed that 124 out of 201 subjects scored 37 or above in Tampa Scale of Kinesiophobia, which shows $61.69 \%$ of the patients post ACL reconstruction had Kinesiophobia i.e. fear of reinjury, present in them. This study also reveals that the presence of Kinesiophobia to that of absence in males is $3: 2(95: 63=1.50)$ and in females is $2: 1(29: 14=2.07)$. Which means women are at a greater risk on kinesiophobia. The percentage affection in males is $60.12 \%$ and in females is $67.44 \%$.

This study group investigates the prevalence of Kinesiophobia in young adults. Age group 18-35 years was included in the young adult age group [13]. 
Medvecky MJ, et al. in their study have stated that only $63 \%$ returned to their preinjury level and the fear of injury that is kinesiophobia is an important factors affecting people not returning to their preinjury or back to full functional activity as the reason for it $[11,17]$. Lee DY, et al . also concluded in his study that $28.8 \%$ did not return to their previous level of sports and fear of reinjury is the main reason for his subjects not returning to sports after 5 years of ACL reconstruction [15]. In this study , the author concludes that there is a high prevalence of Kinesiophobia of $61.69 \%$ present in the evaluated subjects. Our study thus states that high prevalence of Kinesiophobia in 4 to 8 weeks post operative supports that it could be a cause of not returning to preinjury level.

The authors have also found that the women are at a higher risk of prevalence of kinesiophobia than males. The ratio of females suffering was 2:1, whereas for males the ratio was 3:2. $60.12 \%$ of males and $67.12 \%$ of females were kinesiophobic which contradicts the study done by Branstrom $\mathrm{H}$, et al. which states that male are more affected [16].

Since such a high prevalence was noted, it supports the study by Clare LArdern, et al. [13] that psychological readiness which can be done by counseling would help in improving results of returning to preinury level.

\section{CONCLUSION}

The authors conclude that there is a high prevalence of kinesiophobia present in post $\mathrm{ACL}$ reconstruction. Also, that women are at a higher risk of getting affected than males.

\section{ABBREVIATIONS}

\section{ACL - Anterior Cruciate Ligament}

\section{ACKNOWLEDGEM ENTS}

I would also like to thank Dr. Apurv Shimpi (PT) and Dr. Rachna Dabadghav (PT) for their valuable expertise which helped me to conduct the study successfully. I would also like to thank Dr. Kailash Patil who helped me reach out to my subjects. Lastly, I would like to extend my warm gratitude towards all the subjects who willingly co-operated and participated in the study.

\section{Conflicts of interest: None}

\section{REFERENCES}

[1]. Butler DL, NoyesFR, Grood ES. Ligamentous restraints to anterior-posterior drawer in the humanknee: a biomechanical study. J Bone Joint Surg [Am] 1980;62-A:259-270.

[2]. Kiapour AM, Wordeman SC, Paterno MV, et al. Diagnostic value of knee arthrometry in the prediction of anterior cruciate ligament strain during landing. Am J Sports Med. 2014 Feb; 42(2):312-319.

[3]. Levine JW, Kiapour AM , Quatman CE, et al. Clinically relevant injury patterns after an anterior cruciate ligament injury provide insight into injury mechanisms. Am J Sports Med 2013;41:385-395.

[4]. Quatman CE, Kiapour AM, Demetropoulos CK, et al. Preferential loading of the $A C L$ compared with the MCL during landing: a novel in sim approach yields the multiplanar mechanism of dynamic valgus during ACL injuries. Am J Sports Med 2014; 42:177-186.

[5]. Terese L. Chmielewski, Giorgio Zeppieri, Jr, Trevor A. Lentz, Susan M. Tillman, et al Longitudinal Changes in Psychosocial Factors and Their Association With Knee Pain and Function After Anterior Cruciate Ligament Reconstruction. Phys Ther. 2011 Sep; 91(9): 1351366.PMCID: PMC3169786.

[6]. Celletti Claudia , Castori Marco , La Torreand Giuseppe, Camerota Fillipo. Evaluation of Kinesiophobia and Its Correlations with Pain and Fatigue in Joint Hypermobility Syndrome/EhlersDanlos Syndrome Hypermobility Type. BioM ed Research International, Volume 2013, Article ID 580460.

[7]. Butler DL, NoyesFR, Grood ES. Ligamentous restraints to anterior-posterior drawer in the human knee: a biomechanical study. J Bone Joint Surg [Am] 1980; 62-A:259-270.

[8]. 8. Kiapour A.M. and Murray M.M., Basic science of anterior cruciate ligament injury and Bone Joint Res. 2014 Feb; 3(2):20-31.

[9]. Houben R.M.A., Leeuw M., Vlaeyen J.W.S., Goubert ., Picavet H.S.J. Fear of Movement/Injury in the General Population: Factor Structure and Psychometric Properties of an Adapted Version of the Tampa Scale for Kinesiophobia. Journal of Behavioral Medicine.October 2005;28(5):415-424.

[10]. Vlaeyen JW, Kole-Snijders AM, Boeren RG, van Eek $H$. Fear of movement/(re)injury in chronic low back pain and its relation to behavioral performance. Pain 1995 Sep;62(3):363-72.

[11]. Medvecky MJ, Nelson S Kinesiophobia and Return to Sports After Anterior Cruciate Ligament Reconstruction. Conn Med. 2015 Mar;79(3):155-7.

[12]. Hartigan EH, Lynch AD, Logerstedt DS, Chmielewski TL, Snyder-Mackler L. Kinesiophobia after anterior cruciate ligament rupture and reconstruction: noncopers versus potential copers. Epub 9 September 2013. doi:10.2519/jospt.2013.4514. 
[13]. Clare L, Osterberg Annika, Tagesso Sofin, Gauffin Hakan, Webster Kate E,Kvist Joanna. The impact of psychological readiness to return to sport and recreational activities after anterior cruciate ligament reconstruction . Br J Sports M ed doi:10.1136 bjsports-2014-093842.

[14]. Petry NM . A comparison of young, middle-aged, and older adult treatment-seeking pathological gamblers. Gerontologist. 2002 Feb;42(1):92-9.

[15]. Lee DY, Karim SA, Chang HC Return to sports after anterior cruciate ligament reconstruction - a review of patients with minimum 5-year follow-up. Ann Acad M ed Singapore. 2008 Apr;37(4):273-8.
[16]. Branstrom H, Fahlstrom M. Kinesiophobia in patients with chronic musculoskeletal pain: differences between men and women.J Rehabil Med. 2008 May;40(5):375-80.

[17]. Brand E, Nyland J. Patient outcomes following anterior cruciate ligament reconstruction: the influence of psychological factors. Orthopedics. 2009;32:335.

\footnotetext{
How to cite this article:

Rahul Chaitanya Shah,James Ghagare, Ashok Shyam, Parag Sancheti. PREVALENCE OF KINESIOPHOBIA IN YOUNG ADULTS POST ACL RECONSTRUCTION. Int J Physiother Res 2017;5(1):1798-1801. DOI: 10.16965/ijpr.2016.172
} 